Teate, A, Leap, N, Rising S, Homer CSE. (2011) Women's experiences of group antenatal care in Australia - The CenteringPregnancy Pilot Study. Midwifery 27 (2) 138-145.

\title{
WOMEN'S EXPERIENCES OF GROUP ANTENATAL CARE IN AUSTRALIA - THE CENTERINGPREGNANCY PILOT STUDY
}

\section{ABSTRACT}

Objective: To describe the experiences of women who were participants in the Australian CenteringPregnancy Pilot Study. CenteringPregnancy is an innovative model of care where antenatal care is provided in a group environment. The aim of the pilot study was to determine whether it would be feasible to implement this model of care in Australia. Design: A descriptive study was conducted. Data included clinical information from the hospital records and antenatal and postnatal questionnaires.

Setting: Two metropolitan hospitals in Sydney, Australia.

Participants: Thirty-five women were recruited to the study and 33 ultimately received all their antenatal care (8 sessions) through five CenteringPregnancy groups.

Findings: Difficulties with recruitment within a short study timeline resulted in only 35 (20\%) of 171 women who were offered group antenatal care choosing to participate. Most women chose this form of antenatal care in order to build friendships and support networks. Attendance rates were high and women appreciated the opportunity and time to build supportive relationships through sharing knowledge, ideas and experiences with other women and with midwives facilitating the groups. The opportunity for partners to attend was identified as important. Clinical outcomes for women were in keeping with those for women receiving standard care however the numbers were small.

Conclusion: The high satisfaction of the women suggests that CenteringPregnancy is an appropriate model of care for many women in Australian settings, particularly if recruitment strategies are addressed and women’s partners can participate.

Implications for practice: CenteringPregnancy group antenatal care assists women with the development of social support networks and is an acceptable way in which to provide antenatal care in an Australian setting. Recruitment strategies should include ensuring that practitioners are confident in explaining the advantages of group antenatal care to women in early pregnancy. Further research needs to be conducted to implement this model of care more widely. 


\section{WOMEN'S EXPERIENCES OF GROUP ANTENATAL CARE IN AUSTRALIA - THE CENTERINGPREGNANCY PILOT STUDY}

\section{INTRODUCTION}

Antenatal care has been routine practice throughout the world since early in the $20^{\text {th }}$ Century (Oakley, 1984; Moos, 2006). In most developed countries, antenatal care consists of a scheduled program of individual consultations with a health care practitioner, using a doctor or midwife. Many women also undertake childbirth education programs, or 'antenatal classes' where they receive information about pregnancy, labour and birth and parenting. A Cochrane Systematic Review (Gagnon and Sandall, 2007) concluded that the effects of structured antenatal education programmes for childbirth or parenthood remain largely unknown due to a lack of high-quality evidence from trials in this area.

Criticisms of conventional antenatal care are common, principally, prolonged waiting times, lack of continuity of caregiver and hurried staff (Williamson and Thomson, 1996; Laslett, Brown et al. 1997). Women seek antenatal care that provides the physical review of the health and development of their unborn baby; the reassurance and ability to be listened to; and the opportunity for their partner to be included in their care (Clement et al. 1996; Langer, Villar et al. 2002; Handler et al. 2003; Hildingsson and Radestad, 2005).

Group antenatal care takes a different approach. Group antenatal care combines the traditional elements of antenatal care assessment with antenatal education and social support from peers and trained facilitators. In the United States of America (USA), this model has been provided for the past decade and has been named 'CenteringPregnancy' (Rising, 1998). In CenteringPregnancy, antenatal care is provided in small groups of eight to twelve women with specially trained facilitators. Women of a similar gestational age join a CenteringPregnancy group after their initial one-to-one 'booking' appointment with a midwife or doctor.

The CenteringPregnancy Pilot Study was conducted in Sydney, Australia in 2006-2007. This paper describes the CenteringPregnancy model of care and reports on the experiences of the women who were involved in the pilot study. 


\section{CenteringPregnancy as a model of care}

CenteringPregnancy, as a model of antenatal care combining assessment, education and support in group settings, has been widely implemented and evaluated in the USA (Rising, 1998; Ickovics et al. 2003; Klima, 2003; Novick, 2004; Rising, 2004; Massey et al. 2006). CenteringPregnancy enables more time to be spent with the health care provider compared with a one-to-one care model (16 hrs in group care versus 3-4 hrs in a one-to-one care model involving eight appointments). This provides opportunities for additional information about pregnancy, labour and birth and parenting to be discussed and for women to learn from, and support, one another (Massey et al. 2006). The model is based on the development of relationships and the provision of social support. It has been suggested that, by taking health care out of an examination room and into a group setting, barriers between health care providers and women are decreased, leading to improved communication (Massey et al. 2006).

CenteringPregnancy has recently been evaluated in two randomised controlled trials (Ickovics et al. 2007; Kennedy et al. 2007). In the first trial ( $n=1047)$, women assigned to group care were significantly less likely to have preterm births compared with standard care: 9.8\% vs. $13.8 \%$ (OR 0.67, 95\% CI 0.44-0.98; $\mathrm{p}=0.045$ ). Women assigned to group care had significantly better psychosocial function and higher rates of satisfaction with care and breastfeeding. There were no differences in costs associated with antenatal care or delivery (Ickovics et al. 2007). Preliminary findings from the second trial ( $n=322)$, suggest that the group model was effective in meeting women's needs in a military setting (Kennedy et al. 2007). Other, non-randomised, studies of CenteringPregnancy have demonstrated improvements in rates of social isolation, prematurity, low birth weight and social and emotional outcomes for women (Ickovics et al. 2003; Grady and Bloom, 2004; Klima et al. 2003; Klima et al 2009).

The premise of CenteringPregnancy is that antenatal care is provided more effectively and efficiently to women in groups (Rising et al. 2004). Learning and support are enhanced by drawing on group resources, in particular the knowledge, experiences and ideas of individual group participants; the potential for empowerment is increased when women are actively involved in monitoring and documenting their health throughout pregnancy (Rising et al. 2004). The format of the model is founded on a set of core concepts known as the 'Essential Elements of CenteringPregnancy’ (Figure 1) (Rising, 1998). These elements provide a 
framework for the groups and are necessary requirements for each site to fulfil in order to be 'registered' as a CenteringPregnancy site, thereby ensuring model fidelity and the potential to contribute to research in this area.

\section{$<$ Insert Figure 1 here $>$}

All the health professionals who facilitate CenteringPregnancy groups are provided with formal training in the 'Essential Elements' through facilitated workshops (Rising et al. 2004). The Centering Healthcare Institute (CHI), previously registered as the Centering Pregnancy and Parenting Association, is a non-profit organisation which provides basic and advanced training for health professionals (Carlson and Lowe, 2006) in the USA. CHI also tracks implementation sites, evaluates the outcomes from these sites, and provides support and guidance for the health professionals involved (Novick, 2004). This formal training and ongoing evaluation are important components of CenteringPregnancy to ensure fidelity of the model.

\section{CenteringPregnancy in Australia}

The reported successes of CenteringPregnancy in the USA led to the development of the Australian CenteringPregnancy Pilot Study. The study aimed to determine whether CenteringPregnancy would be a practical and acceptable model of care for health professionals and organisations and whether it would meet the needs of Australian pregnant women and their families. The model of CenteringPregnancy developed for the Australian pilot study was designed for women with uncomplicated pregnancies at booking, with midwives as the lead carers and facilitators. A successful grant application from the Telstra Community Grants Foundation enabled the employment of a project midwife to coordinate the implementation of the pilot study in collaboration with the research team at the university and a project development group. A process of adapting the CenteringPregnancy model and resources for an Australian context was undertaken with the assistance and support of $\mathrm{CHI}$ in the USA (Figure 2).

$<$ Insert Figure 2 here $>$ 


\section{METHODS}

A descriptive study was undertaken in two suburban metropolitan hospitals in southern Sydney, New South Wales (NSW). Ethical approval for the study was obtained from the relevant area health service and university prior to commencement.

\section{Setting}

One hospital caters for 2500 births per year and provides care for women with uncomplicated pregnancies as well as for those with an identified range of complications. Women who are less than 32 weeks pregnant, or who have severe complications are transferred to a tertiary referral hospital for labour and birth (NSW Department of Health, 2002). Caseload and team midwifery models of care (Homer et al. 2001; Passant et al. 2003) are offered at this hospital. The other hospital caters for 1000 births per year and, for the most part, provides care for women with uncomplicated pregnancies. Both sites provide hospital and community-based antenatal care and 24 hour obstetric, neonatal, and anaesthetic services from onsite and oncall, medical practitioners. Both hospitals offer women a midwifery postnatal care service at home, known as the Midwifery Support Program.

\section{Training of facilitators}

Following a series of information sessions about CenteringPregnancy, midwives, student midwives and a social worker expressed interest in becoming CenteringPregnancy facilitators. They attended a two day 'Introduction to CenteringPregnancy' workshop facilitated by the founder of CenteringPregnancy (Sharon Rising). Further workshops were provided to assist facilitators with the development of group facilitation skills and support for the planning and evaluation of group sessions. Information posters and pamphlets were designed and made available at all of the antenatal clinics. A series of hospital in-service education sessions, just prior to recruitment of women, were also provided to refresh and remind staff of the model and the study.

\section{Recruitment}

The intention was to invite all women with uncomplicated pregnancies who were due to give birth during July 2007 at both hospitals to participate. Many women were not offered the CenteringPregnancy model of care. The reasons included a lack of time, language barriers 
and midwives being unaware of the study or unsure about recommending CenteringPregnancy.

Women identified as having an uncomplicated pregnancy at their first antenatal visit were provided with verbal and written information about CenteringPregnancy and invited to participate. A total of 171 women were offered CenteringPregnancy care with 35 (20\%) accepting. The reasons that women gave for declining are identified in (Table 1). Following recruitment, two women changed their mind about attending the group: one who identified that the times the groups were held did not suit her; and, another who moved out of the area and transferred her care to another maternity unit.

\section{$<$ Insert Table 1 here $>$}

Five CenteringPregnancy groups were ultimately formed. Three were situated in the hospital antenatal clinics and scheduled at different times: 10-12am, 1-3pm and 6.30-8.30pm. The other two groups were located in local community health centres and held between 5.307.30pm and were provided by midwives from a team midwifery model. The three groups held in the antenatal clinics had consistent leadership with the same facilitator and co-facilitator throughout the eight sessions. A social worker assisted the facilitation of one of these groups. The two groups in the community health centres had a consistent group facilitator, but the cofacilitator position was filled by team midwives on a rotational basis. Student midwives participated in three of the groups on a regular basis in order to learn about CenteringPregnancy and to optimise the chances of getting to know women who they might later attend in labour or the postnatal period.

The time of day that the groups were provided generally dictated whether partners and support people attended. Partners or support people were more likely to attend groups provided out of office hours, while the daytime groups were predominantly attended only by women.

\section{Data collection}

Data were collected at several time points. Women's demographic details and clinical outcomes were obtained at recruitment and after discharge from hospital. The hospital records and a computerised database, used to record information on pregnancy, labour and 
birth and postnatal outcomes routinely, were accessed. At their first groups, women were asked to anonymously record their expectations of the group on sheets of paper that were displayed at each of the sessions.

Two self administered questionnaires were used to measure women's experiences. The first was distributed at 36-38 weeks of pregnancy. The initial questions identified which group the woman attended and her current gestation. Women were asked to rate their antenatal care on a 1-10 scale from 'the worst care' to the 'best care'. The remainder of the questions offered women the opportunity to comment further if they wished. Twenty-one statements then measured satisfaction of different aspects of care on a five point Likert scale, ranging from 'very dissatisfied' to 'very satisfied'. These questions were adapted from a version of the Patient Participation and Satisfaction Questionnaire (PPSQ) (Littlefield and Adams, 1987), that was used by Ickovics and colleagues in a CenteringPregnancy trial (Ickovics et al. 2007).

The second questionnaire was posted to women eight weeks after they gave birth. The purpose was to gather women's views of their antenatal care at a time when they would be able to reflect on the significance and relevance of their participation in the CenteringPregnancy groups in relation to their experience of the early weeks of parenthood. The postnatal questionnaire was similar to the antenatal questionnaire with two additional questions. These addressed whether the woman had received any other antenatal care from another health professional and if so, whether this had impacted on their attendance at the CenteringPregnancy group.

Terminology in the CenteringPregnancy documents and evaluation tools from the USA were changed to accommodate the common terms pertinent to the Australian use of the English language. The Australian questionnaire has not been tested for reliability or validity, but relies on the previous use of the original tool from the USA.

Questionnaires were piloted with eight women who were either pregnant or had recently given birth at the study hospitals. They were asked to provide any comments relating to difficulties with the wording of the questionnaires and the length of time needed to read and complete them. Comments were collated and reviewed by the research team and a small number of changes made. 


\section{Analysis}

Quantitative data were initially entered into an Excel spreadsheet and then transferred into Statistical Package for Social Science (SPSS) format for descriptive analysis. The 21 questions adapted from the $P P S Q$, were allocated into five principal aspects of care: 'information and explanation’; 'service delivery'; 'privacy’; ‘support and reassurance’; 'choice'; and 'individualised care for the woman and her family'. The measures of the five point Likert scale were: 'very dissatisfied’; ‘fairly dissatisfied’; 'neutral’; 'fairly satisfied; and 'very satisfied'. The open-ended questions from the questionnaires and data from the group activities were analysed using content analysis to identify common themes.

\section{FINDINGS}

All 33 women who received antenatal care in a CenteringPregnancy group were included in the study. The women ranged in age from 19-41 years (mean=29 years), which is comparable to the mean age of women attending these hospitals for maternity care (NSW Department of Health 2007). The majority ( $n=30$ ) reported being in a stable relationship and most were having their first baby $(\mathrm{n}=28)$. The sample reflected the multicultural nature of the settings (NSW Department of Health, 2007). Less than two thirds were born in Australia ( $n=21)$, five were born in Europe, four on the Indian subcontinent, three in the Asia-Pacific region and two in the Middle East. English was the dominant language spoken at home with only four stating they spoke another language at home. Most women were healthy without medical or obstetric complications.

As is routine practice in maternity units in New South Wales, women completed a psychosocial health assessment at their first visit using the Edinburgh Depression Scale and an 'Antenatal Risk Questionnaire'. Three women identified that they were at risk of depression and six identified significant anxiety and emotional needs. These women were referred to the perinatal mental health team for review prior to commencing CenteringPregnancy care.

\section{Attendance at CenteringPregnancy groups}

Women's attendance at the groups was measured in two ways. The facilitators used an attendance list for each session and the women were asked the number of groups they attended in both the questionnaires. With the exception of women who gave birth before the 
group sessions, the majority attended all eight sessions. Women who did not attend a session were followed up by the midwife facilitators and arrangements were made for an individual consultation. Out of a possible 280 group sessions offered for the five CenteringPregnancy groups, a total of 268 (95\%) group sessions were attended by women. The most common reason for non-attendance was giving birth before the group sessions had been completed (45\%). Work and other commitments was the second most common reason for not attending a group session (27\%).

\section{Clinical outcomes}

Clinical data for labour and birth outcomes were collected for the 33 women. Most women gave birth between 37-42 weeks gestation $(n=29)$. One woman gave birth at 36 weeks and two after 42 weeks. Most women went into labour spontaneously $(n=24)$ with eight requiring augmentation of labour. Six women had their labour induced. Twenty-one women had a spontaneous vaginal birth, four had a vacuum extraction and six had an emergency caesarean section. Two women had an elective caesarean section, one for a breech presentation and the other for uterine fibroids.

All babies were born alive with birth weights ranging from 2065-4500gms. The only baby with a birth weight of less than 2500gms was born at 36 weeks. Three babies had neonatal complications. These were associated with prematurity, interim poor feeding ability and a cerebral abnormality that was not diagnosed in pregnancy. Almost half the women (48\%) chose to go home early and receive care through the Midwifery Support Program. The rate of breastfeeding on discharge from the hospital service was $88 \%$.

\section{Women's expectations of CenteringPregnancy care at the first session}

At the first CenteringPregnancy session, women were asked, 'What you want to get from the group?’ Most women chose group antenatal care to obtain friendship and support (Table 2).

\section{$<$ Insert Table 2 here $>$}

\section{Women's experiences of CenteringPregnancy care: antenatal survey}

The response rate to the antenatal questionnaire was high: 32 of the 33 women who attended the groups completed the questionnaire. When asked to rate their care on a scale from 0-10 (0 representing the worst care and 10 representing the best care) almost all of the respondents 
indicated their care was 9 or higher on the scale. The overall rating had a mean of 9.2. None of the women rated their care lower than 7.

Women's satisfaction with their CenteringPregnancy care was measured by asking them to rate different aspects of their care with a series of 21 statements. The statements were directed at the fine particular aspects of care described earlier. Each of these is reported in the next section and in Table 3. In the interests of parsimony, only the 'very satisfied' ratings are presented in the Table. Any ratings of very or fairly dissatisfied are presented in text.

Most women reported being very satisfied with the information and explanation provided in the groups. A small number of women were neutral (neither satisfied or dissatisfied) or only fairly satisfied in relation to 'procedures and special tests were clearly explained to me before they were done'. The three statements measuring service delivery were rated as very satisfied by the majority of women. Only one woman was very dissatisfied in relation to 'someone could be reached by telephone to answer my question'. Five women reported being neutral or only fairly satisfied about the consultation with other health professionals. Almost all women indicated that they were very satisfied with the five statements related to privacy, support and reassurance. One woman had a neutral response to one of these five statements with a small number only rating these as fairly satisfying. Most women rated being very satisfied with the three statements about choice. A small number were neutral and no one was dissatisfied. The six statements relating to individualised care for the woman and her family were rated highly by almost all women. Only one woman rated any of these statements as fairly dissatisfied, which was the statement - 'my family was included in my care to the degree I wanted'.

In the open ended section, women indicated that they felt the group antenatal care created a supportive environment where they were able to share ideas and discuss different views and opinions. They were reassured by hearing stories of the experiences of other women. This is typified by this woman's comment: 'I really enjoyed having others who were at the same stage of pregnancy as me to talk to and compare feelings and symptoms'.

Women commented that the development of relationships with their peers and the midwives was important and that having their care in groups provided them with the time and opportunity to do this and to develop support networks, for example: 
'The atmosphere in the group was always friendly and relaxing and we always were made to feel comfortable in the group environment. I hope these groups continue to provide other newcomers to Sydney (like me) the opportunity to meet people and build a support network before their babies are born'.

'I have been supported by the midwives who are now familiar to me and new peers'.

Time was an important factor identified by most women, for example one wrote: 'You do not sit around waiting at your clinic appointment which I have friends complain about who have the typical antenatal visits'. Three women however, found that towards the end of their pregnancy, a two hour session was too long, 'I found it a little long. Maybe one and a half hours should be enough'.

$<$ Insert Table 3 here $>$

Women's experiences of CenteringPregnancy care: postnatal survey

The response rate for the postnatal questionnaire was $54 \%(n=18)$. The age range of the babies of the women who responded was between 6-13 weeks. In the postnatal survey, women were asked again to rate their antenatal care. As before, they rated this highly with a mean score of 9.1 (scale of $0-10$ ). None of the women rated their care lower than 7 . Women were asked if they had attended extra or alternative antenatal care during their pregnancy with seven women responding in the affirmative.

Overall, women were very satisfied with their care (Table 3). The majority were very satisfied with the information and explanation provided. No women were neutral, with the remainder being fairly satisfied. Most women were also very satisfied with the service delivery. Two women were fairly dissatisfied with the appropriate consultation with other health providers and the others were fairly satisfied with the rest of these statements. Equally, most women were very satisfied with the privacy, support and reassurance provided.

However, two women were fairly dissatisfied, one with the physical comfort during the visits and one with the emotional support she was provided. Almost all women were very satisfied with the statements about choice.

The statements about individualised care for the woman and her family were rated by most women as very satisfied however one woman was fairly dissatisfied with the assistance with 
future planning and two women were very dissatisfied with the involvement of their family in their care.

The open ended responses indicated that many women benefited from the group discussions. One woman wrote:

'I could discuss concerns immediately with other midwives and have my issues normalised by talking with other pregnant women who I'd got to know well and felt comfortable with'.

The sharing of thoughts, feelings, opinions and experiences in the facilitated environment seemed to enhance women's learning and their sense of being cared for and supported. This was described by one woman in terms of enhanced well being:

'Being part of a group brought great laughter and even more joy to the pregnancy experience. It definitely facilitated a positive vibe and encouraged happiness (warding off depression)'

Four women required more information about the early weeks of parenting and felt that this was not provided as well as the information about pregnancy, labour and birth, and breastfeeding. One woman expressed this as:

'At the time, we were given ample information. I was very well informed for my birth. More information about coping with a newborn would be helpful'

The inclusion of family, partners and support people was highlighted as an important aspect of the group. The groups who included partners were unanimous about the benefits of this involvement, for example: 'I love the men being involved. They need support too.' Three women identified disappointment that they were in groups where partners were not able to attend: 'I wish my partner could attend some of the sessions'.

Fifteen women stated that the support they gained from their CenteringPregnancy group members and the midwives was a fundamental aspect for their satisfaction. The friendships and connections they developed with one another and the reassurance and support they gained from sharing of information and experience in the group enhanced their antenatal care. They reported that their antenatal care was fun and did not think that this would have occurred in one-to-one antenatal care: 
'It felt good being with other pregnant women going through the same stages'

\section{DISCUSSION}

This is the first reported evaluation of the implementation of the CenteringPregnancy model in Australia. While the study was small and was not meant to provide evidence of efficacy or safety, the results suggest that may be a beneficial form of care that has the potential to be implemented and evaluated more widely. Women identified that the type of care they received was positive and satisfying. In particular, they valued the opportunity to develop supportive relationships with both their peers and their midwives. This is in keeping with findings from studies in the USA (Rising et al. 2004; Massey et al. 2006). The women also described group antenatal care as an experience that met their individual needs, enhanced information sharing about their pregnancy, labour and birth and enabled the development of friendship and support networks. This is significant as antenatal care that enables positive and supportive relationships is widely recognised as promoting benefits for the new mother and her family (Courtney et al. 1996; Oakley et al. 1996; Barclay et al. 1997).

Designing health care provision for groups instead of individuals is a relatively new idea that is increasingly attracting attention. Group models of health care, particularly for the management of chronic disease, have begun to emerge and are showing improved clinical outcomes and patient satisfaction (Beck et al. 1997; Scott et al. 2004). Traditionally the experience of group activities for women during the childbearing years has predominantly been with either antenatal education programs or with new mothers groups. More recently, the importance of antenatal groups that promote social support and the sharing of information have been highlighted, citing the groups provided by the Albany Midwifery practice in South East London as an example (Leap and Edwards, 2007). The CenteringPregnancy model of group antenatal care has combined the assessment component of antenatal care with these aspects of education and social support, demonstrating high satisfaction levels for women and providers (Rising, 1998; Grady and Bloom, 2004), and improved clinical outcomes for women and the babies (Ickovics et al. 2003; Ickovics et al. 2007).

The childbirth experience has been shown to be more positive when the woman and her family/partner have been able to develop a relationship with their maternity care practitioner during the antenatal period (McCourt, 1998; Page et al. 2001; Homer et al. 2002; Hildingsson 
and Radestad, 2005; Hodnett, 2006). Although the CenteringPregnancy model does not include intrapartum and postnatal continuity, it enables continuity of care during the antenatal period and the development of a relationship between the woman and the health care provider. This is a vast improvement on the level of continuity that is currently evident in most Western antenatal care systems (Rising, 1998; Massey et al. 2006).

In this study, the predetermined, CenteringPregnancy group structure and adherence to a punctual start and finish time ensured that the women's time was not wasted sitting in clinic waiting rooms. Instead, the two hours of group time were spent communicating and building trust between the women and the midwives facilitating the groups. The facilitated and supportive process of the group enabled women and the midwives to share their knowledge and experiences, enabling a relationship that was not reliant on the professional's knowledge but embraced the shared knowledge of the group.

CenteringPregnancy includes antenatal education as one of its major elements. Antenatal education programs, using many different approaches, are attended by many women worldwide with little evidence to support their efficacy (Svensson et al. 2006; Gagnon and Sandall, 2007). The concept of women experiencing their antenatal care in a group such as CenteringPregnancy aligns itself well with the adult learning approach identified by Svensson and colleagues (2007) in facilitating learning that is individualised.

Recruitment to the CenteringPregnancy groups presented problems with only $20 \%$ of women who were offered the model choosing to participate. There are several possibilities to explain this reluctance. The implementation of a new model of care, such as CenteringPregnancy, is often met with resistance by the proposed recipients of this care (Hart and Bond, 1995). People find the concept of change difficult to understand and are often fearful of engaging with a new process (Greenhalgh et al. 2004). Many women declined CenteringPregnancy group care even when potential advantages were described to them. This could be because midwives in the antenatal clinics did not promote the model as they were unsure of the benefits and felt uncertain about how women would respond. Anecdotal evidence from the experience in the USA suggests that recruitment of women to CenteringPregnancy groups improves once 'word of mouth' enthusiasm from women who have experienced this model reverberates in the local community. This will take time to occur in an Australian setting as the model is so new and different. Further research needs to explore ways that women and 
health care providers can better understand the model of care in order to provide accurate information that will improve recruitment.

This study is a useful adjunct to previous research on CenteringPregnancy and provides evidence that this model of care has benefits in a non-USA context. It is, however, limited by study size, design and the lack of an economic analysis. The small number of participants restricts the overall findings and the subsequent generalisability of the study. Future studies should explore reasons for uptake of the model of care, both from the perspective of the women and the health care professionals. A randomised controlled trial in an Australian context needs to be conducted which would include a comprehensive cost analysis to determine the economic ramifications. Trials in other settings in Australia and with more diverse populations would also be important in the future.

Despite the limitations, the study is an integral step towards the development of a larger study involving CenteringPregnancy antenatal group care in Australia. Particular attention needs to be paid to the enthusiastic response of women who attended the groups with their partners and the fact that women who attended the women-only groups believed that not having their partners at the group was a disadvantage of their group antenatal experience. Other areas that need further exploration include the expressed needs of some women for more privacy and individualised care.

\section{CONCLUSION}

CenteringPregnancy is an innovative model of facilitated group antenatal care, incorporating assessment, education and support. The Australian CenteringPregnancy pilot study is the first time the feasibility of this model of antenatal care has been undertaken in this country. The results from this study propose that CenteringPregnancy care was an acceptable model of care for the women in this study. Further research is required to implement it in other settings in Australia. This study helps inform future research in this area. 


\section{REFERENCES}

Barclay, L., Everitt, L., Rogan,F., Schmied,V., Wyllie, A. 1997. Becoming a mother - an analysis of women's experience of early motherhood. Journal of Advanced Nursing 25(4), 719-28.

Beck, A., Scott, J., Beck, A., Scott, J., Williams, P., Robertson, B., Jackson, D., Gade, G. 1997. A randomized trial of group outpatient visits for chronically ill older HMO members: the Cooperative Health Care Clinic. Journal of the American Geriatrics Society 45(5), 543-9.

Carlson, N.S., Lowe N.K. 2006. Centering pregnancy: a new approach in prenatal care. MCN: The American Journal of Maternal/Child Nursing 31(4), 218-23.

Clement, S., Sikorski, J., Wilson,J., Das,S., Smeeton, N. 1996. Women's satisfaction with traditional and reduced antenatal visit schedules. Midwifery 12(3), 120-128.

Courtney, R., Ballard, E., Fauver, S., Gariota, M., Holland, L. 1996. The partnership model: working with individuals, families, and communities toward a new vision of health. Public Health Nursing 13(3), 177-86.

Gagnon, A.J., Sandall J. 2007. Individual or group antenatal education for childbirth or parenthood, or both. Cochrane Database of Systematic Reviews Issue 4. Cochrane Library, Oxford.

Grady, M.A., Bloom K.C. 2004. Pregnancy outcomes of adolescents enrolled in a CenteringPregnancy program. Journal of Midwifery \& Women's Health 49(5), 412-20.

Greenhalgh, T., Robert, G., Macfarlane, F., Bate, P., Kyriakidou, O. 2004. Diffusion of Innovations in Service Organizations: Systematic Review. The Milbank Quarterly 82(4), 581629.

Handler, A., Rosenberg, D., Rosenberg, D., Raube, K., Lyons, S. 2003. Prenatal care characteristics and African-American women's satisfaction with care in a managed care organization. Women's Health Issues 13(3), 93-103.

Hart, E., Bond, M. 1995. Action Research for Health and Social Care. Open University Press, Buckingham

Hildingsson, I., Radestad, I. 2005. Swedish women's satisfaction with medical and emotional aspects of antenatal care. Journal of Advanced Nursing 52(3), 239-49.

Hodnett, E. 2006. Continuity of caregivers for care during pregnancy and childbirth. Cochrane Database of Systematic Reviews Issue 4. Cochrane Library, Oxford.

Homer, C.S.E., Davis, G.K., Brodie, P.M., Sheehan, A., Barclay, L.M., Wills, J., Chapman, M.G. 2001. Collaboration in maternity care: a randomised controlled trial comparing 
community-based continuity of care with standard hospital care. BJOG: An International Journal of Obstetrics and Gynaecology 108(1), 16-22.

Homer, C.S.E., Davis, G.K., Cooke, M, Barclay, L.M. 2002. Women's experiences of continuity of midwifery care in a randomised controlled trial in Australia. Midwifery 18(2), 102-12.

Ickovics, J., Kershaw, T.S., Westdahl, C., Magriples, U., Massey, Z., Reynolds, H., Rising, S.S. 2007. Group prenatal care and perinatal outcomes: a randomized controlled trial. Obsterics and Gynecology 110(2), 330-39.

Ickovics, J., Kershaw, T.S., Westdahl, C., Rising, S.S., Klima, C.S., Reynolds, H., Magriples, U. 2003. Group prenatal care and preterm birth weight: Results from a matched cohort study at public clinics. Obsterics and Gynecology 102(5), 1051-7.

Kennedy, H., Farrell, T., Paden, R., Hill, S., Jolivet, R., Rising, S.S. 2007. Enhancing Family Readiness through Group Prenatal Care. Paper presented at the National TRICARE Conference (US Military), Washington, DC.

Klima, C. 2003. Centering Pregnancy: A model for pregnant adolescents. Journal of Midwifery and Women's Health 48(3), 220-225.

Klima, C., Norr, K., Vonderheid, S., Handler, A. 2009. Introduction of CenteringPregnancy in a Public Health Clinic. Journal of Midwifery \& Women's Health 54(1), 27-34.

Langer, A., Villar, J., Romero, M., Nigenda, G., Piaggio, G., Kuchaisit, C., Rojas, G., AlOsimi, M., Miguel Belizan, J., Farnot, U., Al-Mazrou, Y., Carroli, G., Ba'aqeel, H., Lumbiganon, P., Pinol, A., Bergsjo, P., Bakketeig, L., Garcia, J., Berendes, H. 2002. Are women and providers satisfied with antenatal care? Views on a standard and a simplified, evidence-based model of care in four developing countries. BMC Women's Health 2(7), 1-10.

Laslett, A., Brown, S., Lumley, J. 1997. Women's views of different models of antenatal care in Victoria, Australia. Birth 24(2), 81-89.

Littlefield, V.M., Adams B.N. 1987. Patient participation in alternative perinatal care: impact on satisfaction and health locus of control. Research in Nursing \& Health 10(3), 139-48.

Massey, Z., Rising, S., Ickovics, J. 2006. CenteringPregnancy group prenatal care: Promoting relationship-centered care. Journal of Obstetric, Gynecologic, \& Neonatal Nursing 35(2), 286-94.

McCourt, C., Page, L., Hewison,J. 1998. Evaluation of one-to-one midwifery: women's responses to care. Birth 25(2), 73-80.

Moos, M. 2006. Prenatal Care: Limitations and Opportunities. Journal of Obstetric, Gynecologic, and Neonatal Nursing 35(2), 278-285.

Novick, G. 2004. CenteringPregnancy and the current state of prenatal care. Journal of Midwifery \& Women's Health 49(5), 402-411. 
NSW Department of Health. 2002. Guide to the Role Delineation of Health Services. NSW Department of Health, Sydney.

NSW Department of Health. 2007. New South Wales Mothers and Babies Report 2005:

NSW Health Public Bulletin 18. NSW Department of Health, Sydney.

Oakley, A. 1984. The Captured Womb. Blackwell, Oxford.

Oakley, A., Hickey,D., Rajan, L., Rigby, A. 1996. Social support in pregnancy: does it have long-term effects? Journal of Reproductive and Infant Psychology 14, 7-22.

Page, L., Beake, S., Vail, A., McCourt, C., Hewison, J. 2001. Clinical outcomes of one-toone midwifery practice. British Journal of Midwifery 9(11), 700-6.

Passant, L., Homer, C.S.E, Wills, J. 2003. From student to midwife: the experiences of newly graduated midwives working in an innovative model of midwifery care. Australian Midwifery 16(4), 18-21.

Rising, S.S. 1998. CenteringPregnancy: An interdisciplinary model of empowerment. Journal of Nurse-Midwifery 43(1), 46-54.

Rising, S.S., Kennedy, H.P., Klima, CS 2004. Redesigning prenatal care through CenteringPregnancy. Journal of Midwifery \& Women's Health 49(5), 398-404.

Scott, J.C., Conner, D.A., Venohr, I., Gade, G., McKenzie, M., Kramer, A.M., Bryant, L., Beck, A. 2004. Effectiveness of a Group Outpatient Visit Model for Chronically Ill Older Health Maintenance Organization Members: A 2-Year Randomized Trial of the Cooperative Health Clinic. Journal of the American Geriatrics Society 52(9), 1463-1470.

Svensson, J., Barclay, L., Cooke, M. 2006. The concerns and interests of expectant and new parents: assessing learning needs. Journal of Perinatal Education 15(4), 18-27.

Williamson, S., Thomson, AM. 1996. Women's satisfaction with antenatal care in a changing maternity service. Midwifery 12(4), 198-204. 


\section{Figure 1: Essential elements of CenteringPregnancy}

- Health assessment occurs within the group space

- Women are involved in self-care activities

- There is stability of group leadership

- A facilitative leadership style is used

- Each session has an overall plan

- Attention is given to core content; emphasis may vary

- The group conduct honours the contribution of each member

- The group is conducted in a circle and group size is optimal to promote the process

- The composition of the group is stable, but not rigid

- Involvement of family support people is optional

- Group members are offered time to socialise

- There is on-going evaluation of outcomes 


\section{Figure 2: Guidelines for the Australian Pilot Study model of CenteringPregnancy}

- The Australian CenteringPregnancy model of care consists of a one-to-one 'booking' visit followed by 8 two hour sessions through pregnancy.

- The first group meeting occurs between 16-20 weeks of pregnancy

- The groups are facilitated by two midwives or one midwife and one student midwife

- Each group ideally contains 8 - 12 women who are due to have their babies in the same month

- Each woman has an individual check-up performed by the midwife.

- The check up occurs on a floor mat located just outside the group circle but within the group space

- The sessions focus on issues of pregnancy, labour and birth, and parenting

- The discussion is guided by group activities paying attention to group dynamics

- Individual appointments with a doctor/allied health professional are undertaken if required 
Table 1: Reasons for declining CenteringPregnancy at the first antenatal visit

\begin{tabular}{ll}
\hline No reason given & 28
\end{tabular}

Child care responsibilities make group care difficult 25

Work commitments make group care difficult 12

Wanting shared care with GP (more flexible and close to home) 13

$\begin{array}{ll}\text { Groups a bigger time commitment than routine antenatal care } & 8\end{array}$

Wanting one to one antenatal care or not liking groups 12

Baby due in a different month 10

$\begin{array}{ll}\text { Other* } & 22\end{array}$

*Other reasons included: limitations in English language ability; the group time or day did not suit; waiting to go to the birth centre/homebirth model; moving house so transferring to another hospital; wanting partner to be more involved; and transport not available at the time of the group. 
Table 2: Women's expectations of CenteringPregnancy at their first group

\begin{tabular}{ll}
\hline \multicolumn{1}{c}{ Theme } & \multicolumn{1}{c}{ Examples of women's responses } \\
\hline Friendship & An opportunity to network and make friends \\
& A way to connect early especially for after the birth \\
Reassurance & A place to get reassurance \\
& An opportunity to talk about concerns \\
Support & An opportunity to get support \\
& Way for more involvement for guys (partners) \\
Sharing & Share ideas and experiences \\
& Hear other peoples experiences and different experiences \\
Information & Get information about birth and be confident with a new baby \\
& Have more time with midwives to ask questions \\
A fun alternative & Find a different way to have antenatal care \\
& Excited about having fun and being supported \\
\hline
\end{tabular}


Table 3: Women's rating of CenteringPregnancy care in the antenatal and postnatal periods

\begin{tabular}{|c|c|c|}
\hline & \multicolumn{2}{|c|}{$\begin{array}{l}\text { Rated as 'Very } \\
\text { Satisfied' }\end{array}$} \\
\hline & $\begin{array}{c}\text { Antenatal } \\
\mathrm{N}=33 \\
\mathrm{~N}(\%)\end{array}$ & $\begin{array}{c}\text { Postnatal } \\
\text { N=18 } \\
\text { N (\%) }\end{array}$ \\
\hline \multicolumn{3}{|l|}{ Information and Explanation } \\
\hline $\begin{array}{l}\text { Procedures and special tests were clearly explained to me before they } \\
\text { were done }\end{array}$ & $26(79)$ & $14(78)$ \\
\hline Helpful information was given to me about my pregnancy & $31(94)$ & $16(89)$ \\
\hline Someone was available to talk with me at my visits & $30(91)$ & $17(94)$ \\
\hline My questions were answered honestly and openly & $32(97)$ & $17(94)$ \\
\hline \multicolumn{3}{|l|}{ Service Delivery } \\
\hline Someone could be reached by telephone to answer my questions & $26(79)$ & $13(72)$ \\
\hline $\begin{array}{l}\text { Other health care professionals were consulted about my care } \\
\text { appropriately }\end{array}$ & $26(79)$ & $14(78)$ \\
\hline $\begin{array}{l}\text { Someone knew about my individual health concerns and provided } \\
\text { appropriate care }\end{array}$ & $30(91)$ & $15(83)$ \\
\hline \multicolumn{3}{|l|}{ Privacy, Support and Reassurance } \\
\hline I felt physically comfortable during my visits & $29(88)$ & $15(83)$ \\
\hline I was given emotional support & $27(82)$ & $13(72)$ \\
\hline Someone was warm and caring & $29(88)$ & $18(100)$ \\
\hline My privacy was protected & $28(85)$ & $15(83)$ \\
\hline I was treated with respect & $32(97)$ & $18(100)$ \\
\hline \multicolumn{3}{|l|}{ Choice } \\
\hline I was allowed choices with my care & $28(85)$ & $17(94)$ \\
\hline My wishes were taken into consideration about medications & $25(76)$ & $17(94)$ \\
\hline My wishes were taken into consideration about activity and exercise & $25(76)$ & $16(89)$ \\
\hline \multicolumn{3}{|l|}{ Individualised care for the woman and her family } \\
\hline Someone helped me with future planning for me and my baby & $23(70)$ & $11(61)$ \\
\hline My family was included in my care to the degree I wanted & $20(61)$ & $14(78)$ \\
\hline My wishes were taken into consideration about procedures & $27(82)$ & $17(94)$ \\
\hline My wishes were taken into consideration about family involvement & $28(85)$ & $17(94)$ \\
\hline I was allowed to actively participate in my own care & $30(91)$ & $17(94)$ \\
\hline I could voice my opinions about my care & $32(97)$ & $18(100)$ \\
\hline
\end{tabular}

The measures of the five point Likert scale were: 'very dissatisfied'; 'fairly dissatisfied'; 'neutral'; 'fairly satisfied; and 'very satisfied'. Only 'very satisfied' ratings are reported in this Table. 
